\title{
PENGKOMBINASIAN PERMAINAN ANAK DENGAN MATA PELAJARAN SEKOLAH DASAR KEPADA GURU SEKOLAH DASAR KOTA DEPOK
}

\author{
Combination Of Childrens Games With Elementary School Lessons For Elementary School \\ Teacher In Depok City
}

\author{
Iim Marfu'ah ${ }^{1)}$, Finata Rastic Andrari' ${ }^{2)}$, Tuty Kurniawaty Saragih ${ }^{3)}$ \\ ${ }^{123}$ Program Studi Informatika Universitas Indraprasta PGRI \\ Email: marfuahiim@gmail.com
}

\begin{abstract}
ABSTRAK
Salah satu kendala dalam proses pembelajaran di kelas adalah siswa yang kurang aktif dalam kegiatan belajar dan mengajar. Hal ini disebabkan salah satunya adalah karena kurangnya kreativitas guru dalam merancang metode pembelajaran. Sekolah Dasar Pembangun dan MI Ri'ayatul Athfaal adalah salah satu sekolah yang mengharuskan guru-gurunya untuk kreatif dalam merancang metode pembelajaran, namun kurangnya wawasan menyebabkan belum optimalnya keaktifan siswa di kelas. Metode pelaksanaan pada kegiatan ini adalah berupa pelatihan pembuatan peraga dengan mengkombinasikan permainan domino dan ular tangga dengan materi pelajaran. Kegiatan ini dinilai efektif karena guru dapat mengembangkan dan mengkaitkan permainan anak dengan materi pelajaran yaitu menghasilkan alat peraga permainan yang dikaitkan dengan mata pelajaran. Manfaat pelatihan ini membantu guru MI Ri'ayatul Athfaal dan SD Pembangunan lebih kreatif dalam mengkombinasikan permainan dengan mata pelajaran sehingga dapat tercipta suatu situasi belajar yang kondusif dan sehingga meningkatkan kualitas guru dalam kegiatan pembelajaran. Setelah proses pendampingan kegiatan pelatihan di SD Pembangun dan MI Ri'ayatul Athfaal, setiap guru sudah menghasilkan minimal satu media pembelajaran berupa permainan yang dikaitkan dengan mata pelajaran yang diampu oleh masing-masing guru. Guru dapat mengkombinasikan mata pelajaran matematika dan permainan domino. Tiap kartu domino berisi beberapa operasi hitung. Beberapa operasi hitung yang menghasilkan angka yang sama bisa dipasangkan.
\end{abstract}

Kata kunci: permainan, ular tangga, domino, efektif

\section{ABSTRACT}

One of the problems in the learning process in the classroom is that students are less active in teaching and learning activities. This is because one of them is due to the lack of creativity of teachers in designing learning methods. Builder Elementary School and MI Ri'ayatul Athfaal is one of the schools that requires teachers to be creative in designing learning methods, but the lack of insight causes students' activity in the classroom to be not optimal. The implementation method in this activity is in the form of training in making props by combining domino and snake and ladder games with the subject matter. This activity is considered effective because teachers can develop and link children's games with subject matter, namely producing game props that are associated with subjects. The benefits of this training help MI Ri'ayatul Athfaal and SD Pembangunan teachers to be more creative in combining games with subjects so that a conducive learning situation can be created and thus improve the quality of teachers in learning activities. After the mentoring process for training activities at SD Pembangunan and MI Ri'ayatul Athfaal, each teacher has produced 
at least one learning media in the form of games associated with the subjects taught by each teacher. Teachers can combine math subjects and domino games. Each domino contains several counting operations. Multiple arithmetic operations that produce the same number can be paired.

\section{Keywords: game, snake and ladder, domino, effective}

\section{PENDAHULUAN}

Proses belajar yang menyenangkan dan menarik adalah dambaan guru dan siswa. Suasana yang menyenangkan dalam kelas membuat siswa menjadi lebih termotivasi dalam mengikuti proses belajar, sehingga tujuan pembelajaran bisa terwujud. Sekolah Dasar Pembangun dan MI Ri'ayatul Athfaal adalah salah satu sekolah yang mengharuskan guru mampu menciptakan suasana proses belajar mengajar yang menyenangkan serta melibatkan siswa untuk aktif.

Berdasarkan observasi yang dilakukan tim pengusul di SD Pembangun dan di MI Ri'ayatul Athfaal, pihak sekolah sudah sering mengadakan pelatihan untuk mengembangkan kompetensi guru, tetapi pada kenyataannya sebagian guru masih bingung dalam menciptakan suasana proses belajar yang menyenangkan. Guru-guru lebih sering melibatkan teknologi dalam proses belajar mengajar seperti menggunakan software pembelajaran untuk menjelaskan materi kepada siswa. Pada kenyataanya siswa hanya sesaat melihat hal yang menarik tetapi abstrak dan mereka tidak bisa mengoperasikan software tersebut secara bebas, sehingga siswa hanya bisa berimajinasi, pasif, kurang aktif dan berinteraksi dalam pembelajaran.

Pelaksanaan pengabdian masyarakat ini bertujuan untuk menambah wawasan mengenai bermanfaatnya suatu permainan anak dalam pembelajaran di sekolah dan memberikan pengetahuan kepada guru bahwasannya ada cara yang lebih efektif untuk menarik minat belajar siswa dan menghilangkan kecemasan siswa untuk belajar.
Ada beberapa teori yang menjelaskan tentang permainan, yaitu : (1) Menurut Gross permainan harus dipandang sebagai latihan fungsi-fungsi yang sangat penting dalam kehidupan dewasa nanti. (2) Menurut Hall permainan merupakan sisasisa periode perkembangan manusia waktu dulu tetapi yang sekarang perlu sebagai stadium transisi dalam perkembangan individu. (3) Schaller berpendapat bahwa permainan memberikan kelonggaran sesudah orang melakukan tugasnya dan sekaligus mempunyai sifat membersihkan. Permainan adalah sebaliknya dari bekerja.

(4) Seorang ahli psikologi Rusia Ljublinkaja (1961) mamandang permainan sebagai pencerminan realitas, sebagai bentuk awal memperoleh pengetahuan. (Monks, 1982).

Menurut Ardini dan Lestariningrum (2018:6) dalam kegiatan stimulasi perkembangan anak kegiatan bermain memiliki beberapa manfaat, diantaranya: (1) menjadi salah satu cara bagi pendidik untuk mengamati dan melakukan asesmen terhadap anak (2) menjadi media terapi dan intervensi bagi anak yang memiliki kebutuhan khusus (3) pengembangan berbagai aspek perkembangan mengasah ketajaman panca indera pengembangan keterampilan fisik. Tanpa anak sadari, kegiatan bermaian memiliki beberapa fungsi, diantaranya : (1) memanfaatkan energi berlebih pada anak, (2) memulihkan tenaga setelah bekerja dan merasa jenuh, (3) melatih keterampilan tertentu, (4) mengembangkan semua aspek perkembangan, (5) membantu anak mengenali lingkungan dan membimbing 
anak mengenali kekuatan maupun kelemahan pada dirinya, (6) memberikan kesempatan proses berasosiasi pada anak untuk mendapat dan memperkaya pengetahuan.

Berikut ini ciri-ciri bermain pada anak yaitu: 1) dilakukan berdasarkan motivasi dari dalam diri anak, dan untuk kepentingan sendiri. Jadi, tidak ada paksaan dari orang lain; 2) memunculkan emosi positif yang kemudian dirasakan anak, seperti senang, antusias, dan lain sebagainya; 3) fleksibel, yaitu anak mudah beralih dari satu aktivitas ke aktivitas lain, serta tidak ada batasan harus bermain apa; 4) lebih menekankan proses daripada hasil akhir. Ketika bermaian, anak tidak mendapatkan tekanan untuk mencapai nilai atau prestasi tertentu; 5) bebas memilih.anak bebas menentukan cara bermainnya, memilih mainan yang akan dimainkan, serta menentukan kapan beralih pada aktivitas bermain yang lain; 6) purapura. Ketika bermain, anak seolah terpisah dari dunia nyata. Anak suka bermain dengan imajinasinya (Redaksi: 2013)

Dari pengertian dan beberapa manfaat permainan anak tersebut, maka pengabdian masyarakat yang akan dilakukan di SD Pembangunan dan di MI Ri'ayatul Athfaal akan menjelaskan dan mengenalkan prosedur beberapa permainan anak yang diterapkan pada pembelajaran. Adapun cakupan permainan yang akan dikombinasi dengan materi pelajaran adalah:

1. Permainan ular tangga

2. Permainan kartu domino

Dari latar belakang tersebut di atas, maka tim pelaksana pengabdian masyarakat memberi alternatif penyelesaian dengan memberikan bantuan dalam bentuk pelatihan pengkombinasian permainan domino dan permainan ular tangga dengan materi pelajaran. Kegiatan pengabdian masyarakat ini diharapkan menambah wawasan guru SD Pembangun dan MI Ri'ayatul Athfaal agar dapat memahami, mengerti prosedur mengkombinasikan permainan domino dan ular tangga dengan materi pelajaran dan dapat mengembangkan dan mengkaitkan antara permainan anak lainnya dengan materi pelajaran sehingga dapat tercipta suatu situasi belajar yang kondusif dan sehingga meningkatkan kualitas guru dalam pembelajaran dan memudahkan dalam hal penyusunan instrumen pembelajaran. Berikut tujuan dari kegiatan ini :

1. Memberi pengetahuan tentang jenisjenis permainan anak.

2. Memberi pelatihan kepada guru tentang prosedur mengkombinasikan permainan anak dengan materi pelajaran.

3. Memberikan pemahaman pada guru bahwa ada banyak media, alat peraga dan permainan yang dapat digunakan dalam pembelajaran di sekolah.

4. Memberikan alternatif metode baru dalam mengajarkan materi untuk guru agar siswa dapat berperan aktif dalam pembelajaran di sekolah.

\section{Permasalahan Mitra}

Berdasarkan analisis yang dilakukan oleh tim pengabdian masyarakat maka beberapa permasalahan yang dialami oleh SD Pembangun Depok adalah sebagai berikut:

1. Dukungan dan sarana prasarana dari sekolah sudah cukup baik hanya saja dalam pelaksanaannya belum optimal dalam penggunaanya.

2. Penggunaan metode konvensional dalam pembelajaran.

3. Guru masih belum mengenalkan dan menerapkan permainan-permainan kepada siswa.

Sedangkan beberapa permasalahan yang dialami pada MI Ri'ayatul Athfaal Depok diantaranya adalah :

1. Minat siswa untuk belajar masih rendah terutama pada pelajaran eksak.

2. Siswa kurang berperan aktif dalam pembelajaran.

3. Sarana dan prasarana di sekolah belum optimal. 


\section{SOLUSI DAN TARGET LUARAN}

\section{Solusi Permasalahan}

Solusi yang ditawarkan oleh tim pelaksana dalam melakukan pengabdian masyarakat ini adalah dengan memberikan pelatihan pembuatan dan pemanfaatan media pembelajaran yaitu pembuatan permainan domino dan ular tangga pada materi matematika. Adanya pelatihan yang diberikan diharapkan dapat meningkatkan kemampuan guru dalam membuat permainan domino dan ular tangga dengan melibatkan materi pembelajaran. Adapun prosedur yang dilakukan tim pelaksana dalam melakukan pelatihan bagi guru adalah:

1. Tim pelaksana menyiapkan materi dan program untuk kegiatan pelatihan dan sosialisasi

2. Tim pelaksana menyiapkan desain pelatihan bagi guru.

3. Tim pelaksana menyiapkan sarana dan prasarana untuk kegiatan pengabdian kepada masyarakat, yang dibantu langsung oleh pihak sekolah.

4. Tim pelaksana melakukan evaluasi dan analisis hasil kegiatan pengabdian kepada masyarakat.

\section{Luaran dan Target Capaian}

Adapun target luaran dari pengabdian ini yaitu permainan-permainan anak yang berisi materi pelajaran guna menambah wawasan mengenai bermanfaatnya suatu permainan anak-anak dalam pembelajaran di sekolah dan memberikan pengetahuan kepada guru bahwasannya ada cara yang lebih efektif untuk menarik minat belajar siswa dan menghilangkan kecemasan siswa untuk belajar. Dari hasil mengkombinasikan permainan anak dengan materi pelajaran diharapkan dapat meningkatkan prestasi belajar siswa.

Target capaian program Pengabdian Kepada Masyarakat berupa:
1. Peningkatan keterampilan guru dalam mengkombinasikan permainan domino dan ular tangga dengan materi pelajaran.

2. Modul

3. Publikasi Ilmiah.

\section{METODE PELAKSANAAN KEGIATAN}

Pelaksanaan kegiatan ini diawali dengan melakukan analisis situasi dan permasalahan mitra, kemudian dilanjutkan dengan pembuatan proposal pengabdian kepada masyarakat. Setelah proposal disetujui dilanjutkan dengan penyusunan jadwal kegiatan dan pembuatan materi kegiatan. Kegiatan ini berupa pelatihan pembuatan media pembelajaran dengan pengkombinasian permainan anak. Permainan yang dikombinasikan dengan mata pelajaran antara lain Permainan Ular Tangga dan Permainan Domino.

Kedua permainan tersebut akan dikembangkan dan diterapkan dalam beberapa mata pelajaran diantaranya pada matematika, IPA, IPS, Bahasa Inggris, PKN, dan Agama. Pada materi pembelajaran tersebut, diharapkan dapat meningkatkan kompetensi guru serta kreativitas guru dalam mengajar, sehingga tercipta suasana belajar mengajar yang menyenangkan, aktif, kreatif serta meningkatkan hasil belajar yang baik bagi siswa itu sendiri.

Kegiatan pengabdian masyarakat ini berupa pertemuan dengan seluruh peserta pelatihan yaitu guru SD Pembangun dan MI Ri'ayatul Athfaal Depok. Dalam pelatihan ini, peserta diberikan penjelasan mengenai rencana kegiatan tim pengabdian masyarakat, setelah itu memberikan pelatihan. Alur kegiatan pelatihan dari awal kegiatan adalah mengenalkan beberapa permainan anak kepada peserta dengan mengacu pada cara permainan dan dipandu oleh tim pengabdian masyarakat. 
Setelah pelaksanaan pelatihan dan sosialisasi, tim pelaksana kembali ke sekolah mitra untuk melakukan evaluasi kegiatan. Evaluasi dilakukan untuk mengetahui pemahaman guru dalam penggunaan teknologi, sehingga hasil dari pelaksanaan pengabdian kepada masyarakat lebih optimal. Bila masih ada kendala yang dialami oleh guru, maka tim pelaksana menjelaskan kembali kepada guru.

\section{HASIL DAN PEMBAHASAN}

Secara umum kegiatan ini dapat dikatakan berhasil. Hal ini diindikasi dengan adanya interaksi dan tanggapan positif dari lingkungan sekolah tentang adanya kegiatan ini. Hal ini juga ditunjukkan dari sikap instansi sekolah khususnya kepala sekolah dan para guru sangat mengharapkan kegiatan ini dapat dikembangkan lagi dengan membuat permainan-permainan yang menantang dan menyenangkan untuk para siswa. Selain itu adanya keberhasilan dari kegiatan pengabdian ini juga dibuktikan dengan hasil media pembelajaran berupa berbagai permainan yang dikombinasikan dengan mata pelajaran sesuai bidang masingmasing oleh sebagian guru yang mengikuti pelatihan.

Setelah proses pendampingan kegiatan pelatihan di SD Pembangun dan MI Ri'ayatul Athfaal, setiap guru sudah menghasilkan minimal satu media pembelajaran berupa permainan yang dikaitkan dengan mata pelajaran yang diampu oleh masing-masing guru. Beberapa contoh diantaranya ditunjukkan pada Gambar 4 dan Gambar 5. Pada Gambar 4 salah seorang guru mengkombinasikan mata pelajaran matematika dan permainan domino. Tiap kartu domino berisi beberapa operasi hitung. Beberapa operasi hitung yang menghasilkan angka yang sama bisa dipasangkan.

Pada Gambar 5 ditunjukkan salah satu contoh karya seorang guru mata pelajaran agama yang mengkombinasikan pelajarannya dengan permainan ular tangga. Pada papan permainan tersebut berisi pertanyaan materi berkaitan dengan pelajaran yang dibahas.

Berdasarkan hasil pelatihan ini diharapkan guru dapat mengoptimalkan permainan-permainan yang ada dengan materi pembelajaran di kelas. Rekomendasi dari tim pengabdian masyarakat hendaknya media pembelajaran berupa permainan domino, ular tangga dan permainan monopoli ini senantiasa dikembangkan oleh guru sehingga dapat meningkatkan minat siswa untuk belajar. Bahkan guru dapat pengembangkan permaian lain dengan dikaitkan dengan materi pelajaran.

Kegiatan pelatihan yang telah dilaksanakan di SD Pembangun dan MI Ri'ayatul Athfaal mendapat respon yang luar biasa dari pihak sekolah dan Guru. Selain itu banyak dari peserta pelatihan/ guru mengharapkan untuk diadakan pelatihan kembali di kemudian hari. Oleh karena itu, Tim Pengabdian Masyarakat Unindra merekomendasikan kepada semua pihak agar dapat diadakan kegiatan pelatihan yang sejenis untuk pengembangan jenis permainan lain pada materi pelajaran. Hal ini sangat diperlukan oleh sekolah untuk menarik minat siswa untuk lebih aktif dan giat belajar.

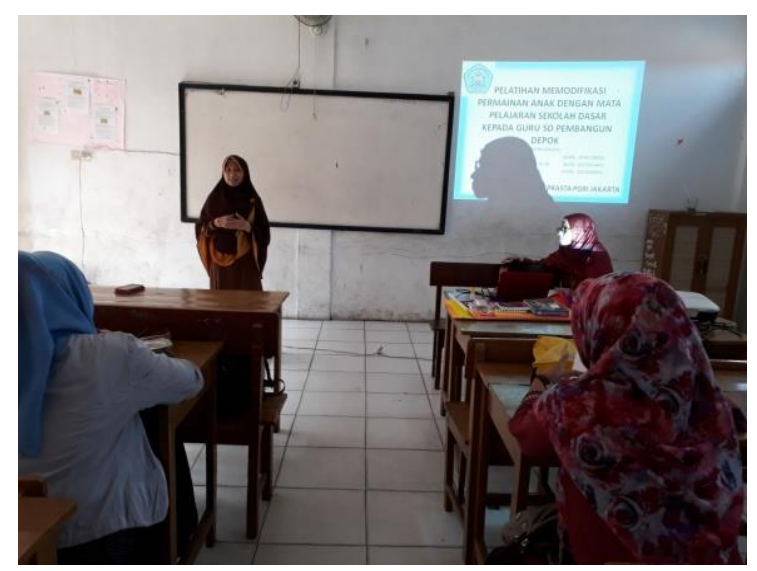

Gambar 1. Pembukaan acara pengabdian masyarakat 


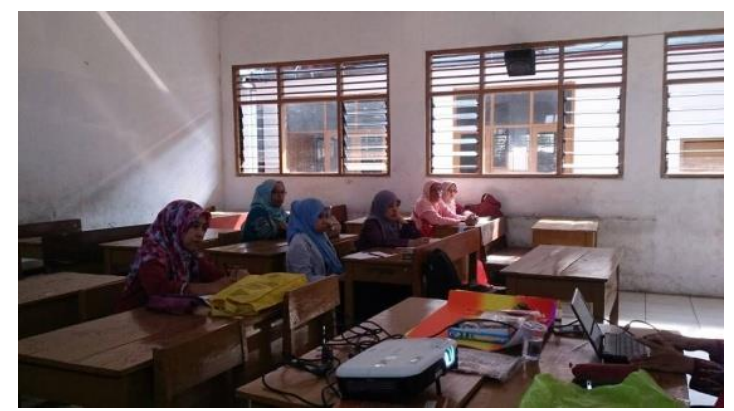

Gambar 2. Peserta pengabdian masyarakat SD Pembangun

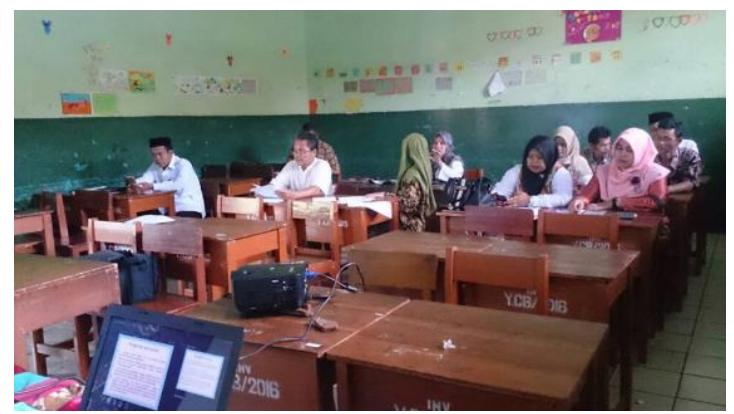

Gambar 3. Peserta Pengabdian Masyarakat MI Ri'ayatul Athfaal

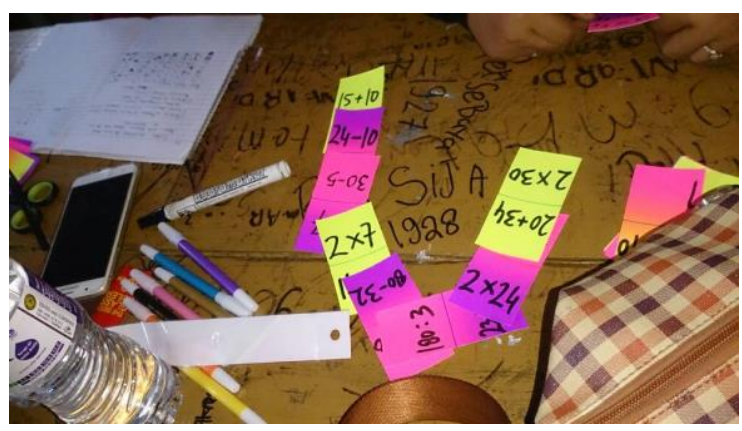

Gambar 4. Hasil pengkombinasian permainan domino dengan materi perkalian

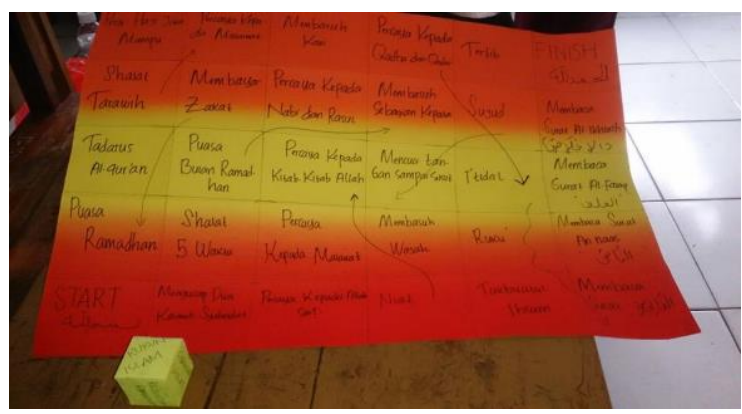

Gambar 5. Hasil pengkombinasian permainan ular tangga dengan mata pelajaran agama

\section{KESIMPULAN DAN SARAN}

\section{Simpulan}

Dari hasil pelatihan, diperoleh kesimpulan:

1. Pelatihan pengkombinasian permainan anak memberikan pemahaman dan kreativitas para guru untuk mengembangkan materi pelajaran dan dikombinasikan dengan berbagai jenis permainan anak.

2. Setiap peserta telah berhasil membuat minimal satu media pembelajaran berupa permainan yang dikombinasikan dengan materi mata pelajaran.

3. Guru menjadi lebih kreatif menggunakan dan membuat berbagai media dan alat peraga untuk menunjang pembelajaran di kelas.

4. Pelatihan ini sangat bermanfaat bagi guru karena memberikan alternatif metode pembelajaran di kelas agar siswa dapat berperan aktif dalam belajar.

\section{Saran}

1. Sebaiknya guru mempersiapkan permainan secara matang sehingga pada saat pelaksanaan dapat berjalan dengan lancar.

2. Sebaiknya guru mencoba terlebih dahulu terhadap permainan-permainan yang dibuat supaya dalam pelaksanaan tidak ada hal yang dapat membuat kecewa para siswa.

3. Guru harus lebih memotivasi siswa agar lebih bersemangat dalam belajar dengan menggunakan permainan maupun tidak menggunakan permainan.

4. Guru dan orang tua selalu memberi dukungan pada peserta didik baik moril maupun materil agar proses pembelajaran lebih kondusif dan efektif. 


\section{DAFTAR PUSTAKA}

Ardini, Pupung Puspa dan Lestariningrum, Anik. (2018). Bermain dan Permainan Anak Usia Dini (Sebuah Kajian Teori dan Praktik). Adjie Media Nusantara, Nganjuk.

R Redaksi. (2015). Definisi Permainan Menurut Para Ahli. Di akses dari http://dyanrch.weebly.com/designcourse/definisi-permainan-menurutpara-ahli tanggal 11 November 2021, pukul 14.00
Redaksi. (2013). Benarkah Anak Sudah Bermain?. Di akses dari https://www.parenting.co.id/balita/be narkah+anak+sudah+bermain/001/00 3/686, tanggal 11 November 2021 pukul 13.00 